\title{
THE SOUL'S SILENT DIALOGUE A NON-APORETIC READING OF THE THEAETETUS
}

Our situation with respect to Plato is paradoxical. Here is a philosopher who emphatically insisted on truth and repudiated persuasion. And yet the community of Plato's admirers finds itself in the predicament that persuasion (or plausibility) seems all it can get: there is not nor was there nor will there be one way to read Plato. There are only temporary agreements among a number of scholars who share certain basic assumptions. And it does not look as if there is anything one can really do about this situation, not for any deconstructionist reasons, but because Plato's dialogues themselves seem so elusive that one cannot help thinking that he intentionally left us with puzzles without the necessary clues that would guide us to a decisive final picture. So we always go on puzzling anew ....

If we are left to our own devices and forced to do creative reading ${ }^{1}$ we can at least try to be explicit about our working hypotheses. For the plausibility of an interpretation depends largely on the plausibility of the basic assumptions. Certain working hypotheses are more promising than others. A particularly fruitful hypothesis, which can be pursued here only for the Theaetetus, is that there are no truly aporetic Platonic dialogues. This must sound like a bold statement, since it flies in the face of the apparent negative end of so many of the dialogues, including the Theaetetus. The intention of this article is not, however, to try to prove this thesis by eliciting a positive solution for all the problems in all the dialogues ${ }^{2}$ - nor even for the Theaetetus. The reason for the denial that there are truly a-poretic dialogues is more limited: I claim only that there is always at least an indication of a poros, a path, that would or could lead to a solution if it were pursued. Why it is not pursued by Plato (or his speakers) is a matter that would have to be contemplated separately for each particular dialogue. ${ }^{3}$ In fact he may sometimes not have had more than a hunch as to where he wanted the discussion to go, or he may have confined himself to the exploration of detours or blind alleys as a necessary preliminary to a successful investigation.

Where in the Theaetetus can one envisage a solution to its main problem, that of giving a satisfactory account of the nature of knowledge? An indication of a possible solution seems to be contained in the final refutation of Theaetetus' claim that knowledge is perception, at $184 \mathrm{~b}-6 \mathrm{e}$. In this article I shall explain how this passage indicates a solution. Then I shall ask what use, if any, Plato makes of 
this possibility in the rest of the dialogue and why he does not overtly bring the discussion to a positive end.

\section{Aisthēsis and epistēmē}

The final distinction between perception and knowledge in this passage amounts, roughly, to the following: sense-perceptions, properly speaking, are only the pathemata of the body as they are perceived by the soul through the sense-organs (184d3). ${ }^{4}$ These faculties (dynameis) themselves are, however, quite uncritical: they do no more than supply us with the sensory experiences themselves. The identification, differentiation and comparison of these perceptions is done by the soul itself. It decides, for example, 'that each one is different from the other but identical to itself ...' (185a/b).

The 'critical' activity of the soul involved here is the employment of the koina, the common terms or concepts needed in these cases; they are being and notbeing, likeness and unlikeness, sameness and difference, unity and number in general. What Socrates is looking for is aptly supplied by Theaetetus. ${ }^{5}$ Without further prompting he accepts Socrates' contention that these 'common concepts' are not given to us through sense-perception but that the soul itself looks after their application: 'the mind itself, by means of itself, considers the things which

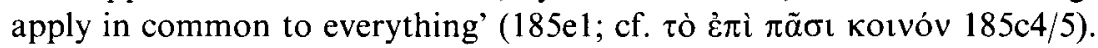

This list seems to be open-ended, for in addition to the aforementioned 'common concepts', Socrates shortly afterwards also includes the beautiful and ugly, the noble and the base (186a). And there is no indication that these are all the concepts there are; we are merely told that these common terms are not derived from sense-perception but are necessary for the mind's reflection on them. For the soul is said to determine their being (ousia) by itself, making calculations (analogizomene, $186 \mathrm{a} 10 ; \mathrm{c3}$ ) and comparisons about them (symballousa, 186b8). ${ }^{6}$

Socrates is rather elaborate and precise here, ${ }^{7}$ so the distinction must be regarded as important: one perceives the sensory qualities (the hardness of what is hard, the softness of what is soft, by touch, 186b2-4); but the soul itself judges (krinei, 186b8) the 'being' of softness and hardness and their contrariety, as well as the nature of their contrariety. As has been remarked by some commentators, there is a certain difficulty about the actual 'work' done by the soul on the level of the pathemata. Does it really only passively receive the impressions or does it not already identify and 'label' them? To discuss this fully here would take us too far afield. One may assume that if sense-perception identifies the objects, then Plato must have a non-predicative or non-propositional 'noticing' in mind. For the 'pathetic's abilities are supposedly common to man and animals and ready for use from birth on; the critical faculty, by contrast, needs development: the calculations (analogismata) about those things (i.e. the pathemata) with respect to 
their being 9 and usefulness are acquired, 'just barely and with time and a lot of difficulty and education by those who in fact do acquire them' (186c $1-5)$.

The rest of Socrates' depiction contains the final proof that perception is not knowledge. Without ascertaining the being (ousia) of the things in question, there is no truth (186c7); if a person does not achieve truth, she will not have knowledge. Therefore there is no prospect of knowledge in those pathemata themselves, but there is knowledge in the calculation about them. Since the affections and the calculations are so different, they cannot be identical: the former are called perceptions (186el); they do not attain being and truth; therefore they do not attain knowledge: hence perception and knowledge are not the same.

This proof puts the coping-stone on the argument against Protagoras. Perceptions themselves may be apseudes (152c5) in the sense that they are incorrigible; ${ }^{10}$ but they only give us 'the feel', they do not disclose the nature of the objects of the affections themselves, their ousia and hoti eston (186b6). ${ }^{11}$

In principle this final distinction between sense-perception and knowledge looks promising. Both are assigned proper functions of their own; yet we do not have a rigid separation between them that would leave the world of appearances to sense-perception only. For regardless of how we have to answer the question whether the koina are the Platonic Forms or not, knowledge is no longer confined to the world of the eternal and immobile, as it was in the middle dialogues. ${ }^{12}$ Reason, rather, reflects on and orders what is perceived. That this is a promising move is confirmed by the fact that the koina, the common concepts that define the proper function of knowledge, are largely identical with the megista gene, the greatest kinds, in the Sophist (254c) (and young Socrates' Forms in the Parmenides).$^{13}$ But the promise of a new determination of the nature of epistemen on the basis of the employment of the common concepts remains unfulfilled. Nothing further seems to be made of the common concepts, nor of the mind's capacity to perform the calculations, the analogismata and syllogismata, which allows it to determine the nature of the affections through the senses, their sameness and difference etc. The puzzled reader must ask himself why this achievement is unceremoniously dropped..$^{14}$

The obvious but unhelpful answer is that Theaetetus, who has not read the Parmenides and does not know what is in store for him in the Sophist, fails to pick up what is all but a definition of knowledge. For in his new definition 'knowledge is true judgement' he makes no mention of what could guarantee the truth of the judgements: i.e. the proper application of the 'common concepts'. Instead, his definition is so vague that any true judgement (even what is known only from hearsay, $200 \mathrm{e}-1 \mathrm{c}$ ) would be included, a vagueness that is widely exploited by Socrates in the last part of the dialogue. Theaetetus is 
obviously too young and inexperienced to realise the importance of Socrates' suggestions concerning epistēmé.

Since, prima facie, nothing more seems to be made of the role of this reflective thinking in the Theaetetus, the question arises what, besides the resemblance of the 'common concepts' to the 'most important kinds' in the Sophist, speaks in favour of the assumption that Plato himself regarded this suggestion as a 'promising line'? Before turning to a search for further traces of promise, which will occupy the rest of this paper, we have to ask ourselves whether the absence of any further emphasis on the common concepts does not rather speak for a straightforward reading of the text, in the sense that Theaetetus' new definition of knowledge as true judgement is exactly the appropriate reaction to the distinction between the functions of perception and knowledge introduced at 184-6. For a conservative reader can quite consistently maintain that the dichotomy under discussion is that between sense-perception and judgement of any kind, not a special kind of judgement that deals with the koina in a conspicuous way. This straightforward reading has one great advantage: it does not leave Plato with a huge gap between (passive) simple sense-perception on the one hand and full knowledge under the guidance of the common concepts on the other. For where would that leave simple judgements like, eg., 'this is red' or 'Socrates is snub-nosed'? This problem is entailed by a 'loaded' reading of the text with emphasis on the explicit use of common concepts, which leaves a large part of the mind's functions unaccounted for, and explains the attractiveness of the alternative solution to attribute such simple judgements to perception itself. 15

I do not suggest that Theaetetus altogether misunderstands Socrates; what he fails to pick up is, rather, a kind of double entendre in Socrates' depiction of the work done by the mind in dealing with the koina. The mind's 'calculations and comparisons' $(186 \mathrm{a}-\mathrm{c})$ may, indeed, stand for no more than our ordinary judgements, as, for instance, that this piece of clay is softer than that one; how much softer it is; what good it would do to use this harder piece of clay to make a dish rather than this softer one. But the 'calculations' may also stand for an explicit and reflective concern with the concepts of hardness and softness themselves: 'their being, and the being of the difference between them' (186b69). ${ }^{16}$ What speaks for the claim that Plato had a stronger interpretation in mind is not only the employment of rather technical vocabulary here ('the being of their oppositeness', 186b7), but most of all Socrates' saying that these calculations are achieved 'just barely, over a long time, through a lot of difficulty and education, for those who in fact do achieve them' $(186 \mathrm{c} 2-4) .{ }^{17}$

The advocates of a 'straightforward' reading will diffuse the strength of this evidence for a stronger reading by arguing that Plato had come to realise that the acquisition of language is, after all, an arduous task for human beings, which gives us the advantage over all the other animals. Whether or not Plato had 
an insight into possible learning disabilities in young children which made him aware of the fact that the acquisition of language cannot be taken for granted, this reading does not do justice to Plato's insistence on the need for paideia to achieve the calculations. The employment of this term suggests strongly that Plato is not here talking about what anyone, after all, who is not hampered in any special way, does achieve. ${ }^{18}$

Socrates, it has to be admitted, makes it easy for Theaetetus to miss this double entendre. If it has been claimed earlier that Socrates has given 'all but a definition of knowledge', it has to be added that he has done so in a very guarded way. For he did not say unequivocally that knowledge is the calculation about the things experienced through sense-perception with the help of the common concepts, but that 'it is contained in them'. Furthermore, Socrates employs rhetorical means that ensure that Theaetetus misses the point. For his final summary of the result of the distinction displays a marked asymmetry: having obtained Theaetetus' answer 'perceiving, of course' to the question 'What name do you give the first: seeing, hearing, smelling, feeling cold, feeling hot?', he does not go on to ask him for the name of the second activity of the soul, as one would expect. Had he continued and asked what name Theaetetus would give to the activity of 'grasping being and truth in our calculations through the common concepts', the answer would no doubt have been 'knowing'. Instead, Socrates breaks off and only draws the conclusion that knowledge is 'something other' than perception and expresses his disappointment that they have only found what knowledge is not (186e).

If this deflection of Theaetetus' attention and the omission of any further explicit discussion of the role of the 'common concepts' as the intellect's critical or calculative capacity to grasp truth and being is the cause of the 'failure' of the discussion in the rest of the dialogue, then the failure to make more of the common concepts in the rest of the Theaetetus must have been a 'planned failure'. ${ }^{19}$ But the 'planned failure' lies as much in Theaetetus' failure to realise the importance of the 'double meaning' of the mind's work, as in Socrates' careful camouflage of it at the critical moment. If Plato, when he wrote the Theaetetus, had already conceived of the employment of the common concepts that he was going to divulge in the Sophist (and practised in the Parmenides), he must have had good reasons to avoid a more direct strategy in the search for knowledge. We should be able to discover the reason for this procedure in the rest of the dialogue. Nothing, at least at first sight, seems to be made of them in the discussion of the possibility of false belief $(187 \mathrm{~d}-200 \mathrm{~b})$, nor in the discussion of the improved definition of knowledge as true belief with an account $(201 \mathrm{~d}-10 \mathrm{e})$. As it will turn out, Plato has very good reasons to lead us on a rather long and winding path in the search for knowledge that does not end with a clear-cut result, rather than show us a straight and narrow path that would end with a positive solution to the whole question. 


\section{The long and winding path}

A brief review of the various stations of this long and winding path is apposite here as a reminder of some of the most pressing problems with the text that stand in need of a solution. After all, many commentators have found this part of the dialogue lacking in compositional unity because there is no very clear strategy in the development of its further stages. A survey of the last part of the Theaetetus must indeed sound like a list of frustrations. For though its two subsections raise interesting questions that are worthy studying in their own right, they all seem to lead nowhere, and the reasons Plato gives for discarding his own suggestions do not always seem to be good reasons. And, worse, in some cases we do not even know why Plato discusses the issues in question at all. What frustrates us in the excursus on the possibility of false belief is (1) the introduction of three obnoxious puzzles that allegedly prove the impossibility of saying what is false (188a-190e), and (2) that nothing is made of the subsequent explanation with the simile of the Wax-Tablet and the Aviary, (187a-200d). This is disappointing since the model of the Wax-Tablet, for example, would at least allow the explanation of certain kinds of mistakes: mistaking one person for another by way of a mismatch of the actual perception with the imprint in our memory (196c5). Even if this explanation does not cover all kinds of errors, at least one kind has been sufficiently cleared up and something like a suggestive model for the soul's retention of memory has been worked out. ${ }^{20}$ The obvious rejoinder, that Plato leaves it to the readers' intelligence to figure this out for himself, may be flattering but it is a rather meagre compensation.

The Aviary, in turn, also has some redeemable features that seem worth stressing: the differentiation between potential and actual knowledge (the 'possessing' vs. the 'having' of a piece of knowledge) would seem rather important, as is conveyed by the initial plausibility of 'getting the wrong bird' in one's mind. It contains at least a good metaphor to characterise, if not to explain, such slips of the mind that we sometimes actually do commit. And both similes contain the message, long overdue, that knowledge is not an all-or-nothing affair, as it had been treated in the puzzles and in some earlier dialogues: making a mistake is not the same thing as not knowing. ${ }^{21}$

Even more frustrating than the fact that all of these suggestions are discarded without any attempts to redeem what is worthy of redemption, is the failure of Theaetetus' final definition of knowledge as 'true belief with an account'; for this looks just like a move one would expect Plato to welcome. To give an account, logon didonai, is a request that we find Socrates making in other dialogues time and again. ${ }^{22}$ Yet none of the meanings of logos are found satisfactory; one cannot help getting the impression that Socrates studiously avoids any more satisfactory interpretation of logos. Instead, he first investigates what look like rather farfetched difficulties, such as the question of the unknowable ultimate elements in 
Socrates' Dream (201d-6b), ${ }^{23}$ and then makes easily refutable suggestions such as the possibility that logos is merely spoken language $(207 \mathrm{~d} / \mathrm{e})$ or that the logos consists in the complete enumeration of all parts $(207 \mathrm{a}-8 \mathrm{~b})$. Only Socrates' very last attempt seems to contain a workable suggestion: that the logos should give us the appropriate distinguishing mark. It is promising since this seems what dialecticians are, after all, to look for, the characteristic that separates the thing in question from all other items of the same kind. ${ }^{24}$

Once again we are left empty-handed since it is pointed out that the distinguishing mark is already necessary for the possession of true opinion. Adding the condition that we must know (rather than just 'opine') the distinguishing mark would make the whole definition hopelessly circular. The reader asks himself why all attempts to save 'true opinion' by the addition 'with an account' are so singularly unsuccessful. Is it because Plato wants to indicate that true opinion can never be changed into knowledge (for reasons insinuated by Plato in Rep. 5)? Or is it because Socrates had confined himself to discuss material entities rather than the Forms, as Cornford would have it?25 The suggestion pursued here, that it is the failure to follow the line indicated by the introduction of the koina, might seem to point in the same direction. Yet, it cannot be so simple. The discussion is much too elaborate and detailed merely to hide the suggestion that we should look for knowledge not 'in the sense perception at all, but in what goes on when the mind is occupied with things by itself, whatever name you give to that' (187a), if that meant the contemplation of the Forms by themselves. For although the soul is supposed to deal with the koina by itself, the subject matter are always sensible objects. At 184-6 it is clearly the sensible qualities that are thus analysed and differentiated. So it cannot be the mere failure to turn away from the world of the senses to the world of the Forms (in the sense of the middle dialogues) that accounts for the negative end of all the attempts in the last part of the Theaetetus.

Many scholars have therefore tried to tie the last part of the Theaetetus together by unearthing a hidden agenda for the dialogue. ${ }^{26}$ The interpretation favoured here will, in fact, try to do something of that sort, except that the agenda is not so very hidden, when one takes a closer look at the text and sees how Plato does employ the common concepts, implicitly if not explicitly, in the last part of the dialogue.

\section{False belief}

A closer scrunity of the text will show that it was not quite correct to say that the koina are simply dropped after $186 \mathrm{e}^{27}$ In fact, Socrates' own elaboration on the question how the soul comes to form its judgements, correctly or incorrectly, does make use of them all the time. It would be a laborious and unrewarding task to go through the text and discuss every single occurrence of the common concepts, 
being and not-being, sameness and difference, with the intention to show that there is more to them than meets the eye at first sight. Since they are the most general terms that are likely to occur in any abstract discussion, Plato may, after all, often make use of them quite unreflectively, that is without noticing that he is applying one of the common concepts. A few examples that support the claim that there is a reflective and constructive use on Plato's side must suffice.

The unobtrusive but significant presence of the koina in the discussion surfaces most in the three paradoxes that introduce the problem of how false beliefs are possible rather than in the Wax-Tablet and the Aviary. This gives the paradoxes a point which has been largely overlooked by commentators.

At first sight it looks as if Socrates is here merely exploiting Theaetetus' inexperience and good-nature ${ }^{28}$ to warm up some old sophistic gimmicks. ${ }^{29}$ In the first paradox $(188 \mathrm{a}-\mathrm{c})$ he points out the impossibility of 'thinking what is false' in the sense of either knowing what you do not know, or of not knowing what you do know. In the second paradox the ambiguity of 'thinking what is not' is used $(188 \mathrm{~b}-9 \mathrm{~b})$. And in the third one, on allodoxia, ${ }^{30}$ we find Socrates exploiting the fact that no one would claim that this one thing is that other when he knows both (190c6). The inadequacy of this last explanation of false belief is so apparent that one wonders why Socrates stoops to take it up; for clearly no one thinks that 'ugly is beautiful' or that 'odd is even'. If Theaetetus had been a bit more precise in the formulation of his own example that one may mistakenly regard (something) ugly as beautiful and vice versa $(189 \mathrm{c})$, it would have been quite obvious that he did not need any enlightenment in that connection.

But when one looks at the text more closely one realises that what Socrates is doing is far from trivial. For it turns out that one of the important issues he tries to work out is what, precisely, happens on the conceptual level when someone 'thinks what is false'. In all three paradoxes he makes unobtrusive but persistent use of the 'common concepts' of sameness, difference, being and not-being. In the first paradox he makes us reflect on the question whether anyone would think that tauta, which he knows/does not know, are not tauta but hetera tina which he knows/does not know (188b4;b7). In the second paradox he is dealing with the improper application of 'not-being' in the assumption that saying what is false is the same as 'saying what is not' (189b1). In the third he is working on the

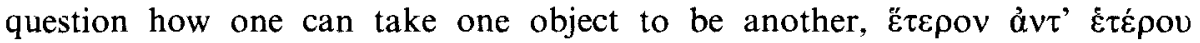
$(189 \mathrm{c} 2 / 3){ }^{31}$

If the paradoxes are supposed to provoke some wholesome reaction in the reader, then it must consist in the realisation that these puzzles would not arise if the common concepts were applied judiciously. I can only indicate what improvement a more reflective employment of the common concepts would convey. Reflection for example on the sense in which one can both know and not know one and the same thing, to auto, would clear up the paradox of knowing what you don't know. For mistakes arise when the identity of the objects or the 
special aspect under which it is regarded is not clearly established, so that it is indeed possible that someone who knows some things believes them to be other things he also knows (188b). ${ }^{32}$ If the identity or the special aspect had been clearly established beforehand we would know and could not be mistaken about what is what. Usually we regard such knowledge as too trivial to even call it 'knowledge' and we do not reflect on it, that Socrates is the same as Socrates and different from Theaetetus who is the same as Theaetetus! But by forcing us to reflect on the question how and under what conditions we may misapply the general concepts Plato brings to our attention what happens when we get it right; this is a point worth making, for we are usually not aware of making any such moves in our minds when we, for example, say 'There is Socrates'. Why even the correct and reflective handling of the common concepts may not justify a claim to knowledge but only to right opinion will be discussed in the last part of this article. The fact that Plato alternates here in his expression between 'knowing' (oide) and 'believing' (doxazei) shows that he has the everyday, non-epistemic, sense of 'knowing' in mind.

No attempt at a full and precise analysis will be made here of the three paradoxes of false belief as 'not knowing what you know', 'thinking what is not', ${ }^{33}$ and 'thinking one thing instead of another', since it would take too long to show how in each case precision about the common concepts, being and nobeing, sameness and difference, would explain the possibility of false belief. In all three cases sufficient reflection on the common concept involved, the particular kind of identity or difference, the qualification of being and not-being, and the factual conditions of their application, would explain and solve the paradox. Whether Socrates' arguments are fair or foul, it is certainly not trivial to draw our attention to the difference between a statement that uses the common concepts explicitly and with the appropriate qualifications (190c), and statements which do not use them with the necessary circumspection (as when I claim that this person over there is Socrates, when I in fact point to someone else, or when I call him ugly while he is in fact beautiful). ${ }^{34}$

Socrates is, unfortunately, not quite as explicit as one might wish (except in so far as the obvious flaws, especially in the refutation of allodoxia, should point us in the right direction); but his claim that a belief is the result of the soul's silent dialogue with itself indicates that this is the salient point. Thinking is explained as a period of self-questioning and -answering performed by the soul: 'And when it has come to a decision, either slowly or in a sudden rush, and it is no longer divided but says one single thing, we call that its judgment' (190a). What does not come to the fore in McDowell's translation is that Socrates uses here not 'one single thing' but to auto, which is clearly one of the common concepts. This is important, however: for the soul's dialogue reaches its conclusion, Plato thus suggests, when the mind rightly or wrongly has established the identity of what it is questioning. 
As Plato indicates, the soul can go astray in its silent dialogue, not in its explicit and circumspect handling of identity-statements, but in its implicit agreement about a thing's identity; there is no question that I could persuade myself that $\mathrm{X}$ is $\mathrm{Y}$, if $\mathrm{I}$ knew $\mathrm{X}$ as $\mathrm{X}$ and $\mathrm{Y}$ as $\mathrm{Y} .{ }^{35}$ We only have to remember another example of such a silent dialogue in Plato, to get a fair idea what Plato had in mind. In the Philebus Socrates spells out such a dialogue which explains how the soul arrives at its results: 'often a person seeing something from a distance doesn't see it very clearly and wants to decide what it is he is seeing ... Our man might ask himself a few questions, like this "What is this that seems to be standing by the rock under a tree?" .. A man in such a case might next make a guess at it. "It's a man" he might say, in answer to himself. Or he may mistakenly suppose what he sees to be a work of some shepherd and say "It's a carving" ...' (38c/d). ${ }^{36}$ The passage in the Philebus merely appeals to our common sense understanding of such mistakes, it does not go into any analysis of the precise path our mind may take when it makes a mistake, nor, of course, does it make any reference to the question of an application of the common concepts; we meet here only with a practical example for our implicit handling of the concept of identity.

The importance of the koina is more explicit in the Theaetetus, even though the common concepts are never again called by that name nor used very conspicuously. But Plato puts sufficient emphasis on the negative side of their employment. As he points out, we do not ever tell ourselves in a silent dialogue that 'the one thing is the other', not in the abstract formulation (190c7), nor in application to a concrete example: 'this ugly thing is beautiful'. If we are fully and properly 'in touch' with the subject matter and classify things as 'the one' and 'the other' and figure out what their sameness or difference consists in, as Plato had recommended in the passage on the common concepts (184-6), no mix-up could occur, and we would end up with the right opinion.

In his exposition of the problem of false belief Socrates had at first treated the possession of the common concepts as an all-or-nothing affair and shown that in this case no error would be possible. This is emphasised at the end of the 'aporetic' passage: 'no one who has both things in what he says and judges and has a grasp of both in his mind, would say and judge that the one is the other (

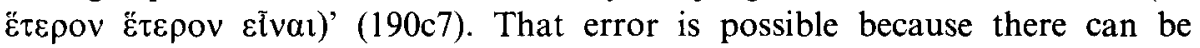
different ways of 'having a grasp' $(\pi \eta 1,191 \mathrm{~b} 1)$ on the object, is confirmed by the simile of the Wax-Tablet. Only when no proper determination concerning the identity and difference of the objects in question is reached, does error occur. In the case of mismatching the visual imprint of one person with the imprint of someone else in one's memory (because of the poor quality of the memory) one might say that no proper silent dialogue of the soul has taken place, and the soul has 'rushed to its conclusion' too soon. It has misapplied one of the koina.

If the soul had achieved a full grasp of the object in its memory and perception

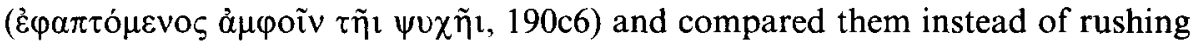


to a conclusion, then error would have been avoided. The soul would, for instance, have come to realise the poor quality of the imprint, or that the 'snub' of the nose and the protrusion of the eyes were not significant enough to ensure that this is Socrates, or it would have reflected on the notorious weakness of memory quite generally. In case of doubt it would have told itself that the grounds for the assertion of the identity of 'the one' and 'the other' were insufficient, and suspended judgement.

The same conclusion can, mutatis mutandis, be drawn for the mathematical example in the Aviary: that a careful handling of the numbers would lead to a successful addition of $7+5$. Why then is Plato so dissatisfied with his own model that he ends up asserting that no acceptable explanation has been reached? Modern critics agree with Plato that 'getting the wrong bird' is not a satisfactory analysis of how we make mistakes in mathematics. I will not go into a detailed analysis; it seems, at any rate, that Plato himself is not satisfied with the explanation that the miscalculation of $7+5=11$ is a case of mistaking 11 for 12. ${ }^{37}$ And this may indeed be the whole point of the Aviary: to show that not all mistakes are simple cases of mis-identification and mismatching in one's memory. Plato may in fact have wanted to indicate as much when he mentions that the question the person asks himself is 'how much' the sum is (196a5 $\pi$ ó $\sigma \alpha \pi$ o $\tau^{\prime}$ $\dot{\varepsilon} \sigma \tau i v){ }^{38}$ To calculate a quantity is not simply to 'grab' a number; but numbers and their properties had explicitly been included among the common concepts whose proper treatment has to be learned with great pains and paideia (185d).

But there is more to Plato's dissatisfaction with the Aviary than that. Mathematical knowledge cannot be depicted as different pieces of beliefs that flutter around in our minds, to be grabbed and missed (cf. 'an epistēmē of 12 instead of an epistemen of 11',199b3). Nor can the success of such grabbing be established by comparing one item carefully with another, as it was the case with the Wax-Tablet, where the object grabbed through the senses can be compared with the image in our memory. No matter how carefully I look at both numbers I will not find out that and why the sum of $7+5$ is not 11 but 12 . The fact that Plato has switched from the search for true/false beliefs in mathematics to the search for knowledge, and points out that we would need further criteria to establish success or failure insinuates that he was quite aware that in mathematics there is no room for a systematic account of isolated true/false opinions. If they are the result of random grabbing, a lucky or unlucky guess, there would be a need for further criteria (another aviary) to establish whether they are correct. A dialogue in the soul that settles mathematical questions must proceed quite differently, and Plato is right when he lets Socrates object to himself that the question of the falsity of such beliefs can only be settled when we know what knowledge is ${ }^{39}$ It would be an endless and futile task to look ad hoc for a different model for each different kind of mistake, and certain kinds of mistakes are not explicable in isolation. Plato has then not settled all questions which are raised in 
the 'excursion' on the conditions of false opinions; he has demonstrated, however, that the calculations (analogismata) of the mind are much more complicated, even in the case of relatively simple questions, than one would at first suppose.

\section{The dream}

The final part of the Theaetetus is in a way the most vexing of all for the introduction of 'true belief with an account' seems to be just the move one would expect Plato to approve of.$^{40}$ But no satisfactory account of "account" is found in the end, and the whole strategy in the last part remains unclear, that is, why Plato discussed the different problems he discusses, and how the discussion hangs together. The greatest obstacle to a clear understanding is the passage at the beginning which contains the discussion of Socrates' Dream (201d8-6c2). First of all there is the question why Socrates thinks he has to refute the claim it makes, that the ultimate elements of all things are unknowable, so that we can know composite wholes but not their ultimate parts. Secondly, there is the question whose theory this is. Thirdly, there is the question whether the refutation offers a real dilemma and not, rather, yet another exploitation by Socrates of Theaetetus' inexperience. For it looks at first like a matter of sheer inexperience when he fails to defend the view that a whole may be more than the sum of its parts. There are many more problems with respect to the Dream Theory, but these three will do at this point.

The first two questions are closely linked together. For the difficulty in explaining what the Dream Theory does here has driven many interpreters to a search for an author other than Plato, on the assumption that he is here refuting some fashionable theory whose consequences, he thought, were standing in the way of any knowledge whatever. As has been argued sufficiently by others, there is no need to look for any other author beyond Plato himself. ${ }^{41}$ No attempt will therefore be made here at yet another detailed interpretation; some indications must suffice to clarify what the gist of the Dream's introduction must be, what difficulty Plato solves, as far as a superficial summary can do that.

Why is Plato concerned with the question of 'unknowable ultimate elements', like the letters in words or particles in physical objects? Some scholars have assumed that the dilemma of the Dream Theory arises if knowledge is restricted to definitions, and definitions are supposed to give an analysis. For in that case the ultimate elements clearly would be undefinable since they have no analysable parts. And the dilemma then confronts us with the unpalatable alternative that the wholes or composites are either nothing but the sum of knowable ultimate parts, or they are different, new entities, not constituted by their parts, and are thus unknowable likewise. 
This interpretation in terms of an analysis of parts and wholes overlooks the fact that this is not the original thesis that Plato's reductio ad absurdum is designed to refute. In the original statement of the dream theorist the problem is not the relationship of parts and wholes but the claim that you cannot say anything proper about ultimate elements, except for naming them (201e2-2c5). For, as Socrates says, 'One cannot go on to say anything else, neither that it is nor that it is not; because in that case, one would be attaching being or not being to it, whereas one ought not to add anything if one is going to express in an account that thing, itself, alone. In fact one should not even add "itself" or "that", or "each" or "alone" or "this", or anything else of that kind. 42 The reason for the need of such abstemiousness is that in the case of such ultimate elements you would add something alien if you attributed anything besides what is proper to them (c.f. oikeios logos, 202a7). And since the elements are simple there is not anything else that is 'proper' to them, so no symploke onomaton that would be oikeion to them is possible, hence they can only be named. ${ }^{43}$

The point is not, as many commentators assume, that one cannot say anything about them at all; there is not here a sudden resurgence of Heraclitean elements (cf. $157 \mathrm{~b} ; 183 \mathrm{a} / \mathrm{b}$ ). If that were so one could not have a true opinion about them either, and they would a fortiori not be candidates for knowledge; but both Theaetetus' exposition of his recollection of the Dream Theory (201c/d) and Socrates' final summary of his explanation of its meaning (202b8-c5) suggest that we do have opinions about them. This claim is crucial and controversial, and therefore needs further defence.

There are some prima facie objections to this reading that should be dealt with first. The formulation Socrates uses when presenting the contrast between the knowable syllables and the unknowable letters is not as clearly in favour of the fact that the letters are 'opinable' as one could wish. It might seem that Socrates at 202 b6 not only wants to say that the elements cannot be defined $(a \log a)$ and known (agnosta), but also that they are not 'opinable', because he only mentions that they are perceptible (aisthèta de); for when he contrasts them with the syllables he does not mention that they, too, can be grasped by 'true opinion' (202b7). In that case, however, the last sentence of Socrates' exposition (202b8c5) could not be taken as a summary of the preceding distinction between knowables and unknowables; it would only depict, in a quite general sense, what happens when one progresses from having a mere doxa (about what is in principle knowable but not yet known) to full knowledge. 'When someone gets hold of the true judgement of something without an account, his mind is in a state of truth about it but does not know it; because someone who can't give and receive an account of something is not knowledgeable about it. But if he gets hold of an account as well, then it is possible not only for all that to happen, but also for him to be in a perfect condition in respect to knowledge (202b-c).' 
What tells against taking this as a general remark that does not apply to the elements is not only that Socrates would thereby fail to sum up what the preceding dichotomy has established; such failure in neatness might not, perhaps, by itself carry sufficient weight. What is much more important is that according to this interpretation Socrates' whole elucidation of Theaetetus' recollection does not actually make the contrast Theaetetus had intended between his two kinds of cases (201c9-d3): the case where we have a true opinion with a logos, which is knowledge; and the case where we have a true opinion without a logos, which is

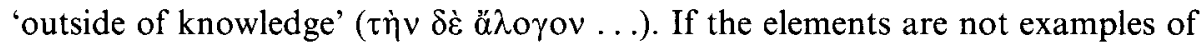
the latter case, then Socrates has not, in fact, given an elucidation of the dichotomy which Theaetetus himself could not fully recollect. This, however, was what Socrates had promised to do $(201 \mathrm{~d} 4 / 5$ : 'The distinction between things which are knowable and things which are not: let's see if what you have heard matches what I have'), and claims at the end of the passage to have done, to both his and Theaetetus' satisfaction (202c5-6: 'Is this the way you heard the dream or was yours different?' - 'No, it was exactly like that'). It seems therefore preferable to regard the first elements as exemplifications of what is not knowable but horribile dictu, opinable. We can, thus, have lots of true opinions about the letters, as long as we are conscious of the fact that this does not mean that we

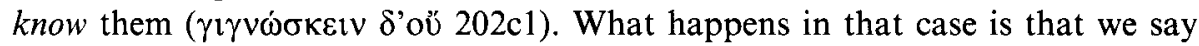

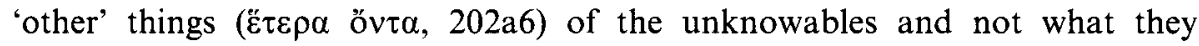
themselves are. ${ }^{44}$ That the Dream Theory does permit us to have true opinions about the elements explains why Theaetetus can go on lustily to describe the letters without being checked by Socrates: they are both aware that such descriptions do not make them knowable (gnōsta, 203c1), since they have no logos that would tell us what 'they themselves are' (203b6).

What has made other scholars refrain from endorsing such an interpretation of the Dream Theory must be the very strangeness and philosophical unattractiveness of the claim that by merely referring to the elements we 'add something' to them. Who would be inclined to propose such a view, except for (albeit for different reasons) the long-dismissed extreme Heracliteans? And why should Plato construct such an elaborate dilemma to refute it? The Dream Theory might seem of much greater philosophical interest if it had been introduced by Plato to defeat the view that all knowledge must be analysis in terms of constitutive parts since it leads to the logical atomism which has found advocates in the later history of philosophy. And the long discussion of the dilemma of parts and wholes can indeed be taken to confirm that this is Plato's real concern. Plato might well be interested in the refutation of such logical atomism, even without having any actual adversary who advocated it; for such a refutation would come in handy as a plea and preparation for an 'interrelational' account of knowledge. The point of the refutation of the Dream Theory would then be that knowledge need not be analysis in terms of constitutive elements, but can also consist in 
establishing the interrelation between the different entities that make up a field of knowledge. ${ }^{45}$

I do not dispute that the move towards an 'interrelation-concept' or 'fieldtheory' of knowledge is the upshot of the final part of the dialogue as a whole. But it does not seem to be the point made or intended by the Dream Theory. Its point is more elementary, and the need to make it arises from what preceded in the dialogue itself. What no one to my knowledge has seen is why Plato himself had a vested interest in clarifying how basic simple elements can be known. If I am not mistaken, the Dream Theory refers the reader back to the introduction of the common concepts at 1846 . For what sounds at first like a mad theory, namely that you cannot say more about the elements than their names (on the ground that even calling them 'this' or 'that' would add something alien to them), could be, mistakenly, regarded as the direct consequence of Plato's own introduction of the common concepts and his depiction of how they are related to the sensible objects.

We have to take a look back again. The common concepts were treated as something different from the sensibles to which they are applied by the mind; and it would be easy to misunderstand Plato as if he had implied that they add something common and not proper to the sensibles to which they are applied by the mind. So it is tempting to draw just the kind of consequence for the common concepts and their relationship to the sensibilia that is articulated in the Dream theory (202a5-8): 'Because those things run about and get added to everything, being different from the things they are attached to, whereas if the thing itself could be expressed in an account and had an account proper to itself, it would have to be expressed apart from everything else. ${ }^{46}$ Plato even gives us a small hint that he is concerned with the relationship between the common terms and the sensibilia, for he mentions that the elements are aisthêta (202b6), a remark which causes trouble for all those who try to interpret the Dream as a refutation of logical atomism and minimal parts (why Plato speaks about elements at all, rather than the sensibilia in general, will be discussed further below).

According to the interpretation favoured here, it is this 'inapplicability-thesis' of the koina in an account which is refuted by a reductio ad absurdum, the dilemma of parts and wholes. The discussion of parts and wholes is just the means to that end, for if you cannot say anything else of the elements, then their having parts would be the only alternative. But, as Theaetetus realises, there are no elements of elements (203b3), and so the first elements remain undefinable. ${ }^{47}$

It is in favour of this interpretation that the indefinability of wholes that are more than the sum of their parts is justified by Plato in exactly the same way as it had been in the case of the simple elements: if we grant that in the case of the

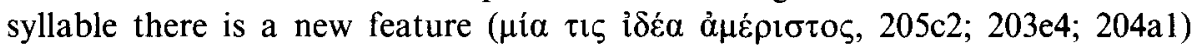
above the parts, for example, their nexus, then this new feature in turn cannot be determined by the application of any common concept or term $(205 \mathrm{c}-\mathrm{d}) .{ }^{48}$ Plato 
explicitly asserts that the inapplicability of any such term is the reason for its

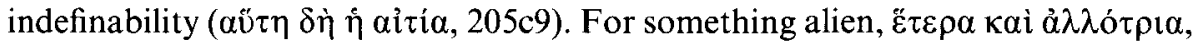
would be added to them; they would, thus, be indefinable and unknowable. The upshot of the dilemma is, then, that the addition-theory must be false; for it makes everything unknowable, not just the elements themselves. The dilemma works, this should be stressed here, only for those who assume that there is knowledge; Plato does not give any further argument for the possibility of knowledge beyond the reductio itself. While it could do nothing to refute the sceptic, it does fulfil the purpose it was introduced to fulfil: to point out why the basic distinction between knowables and opinables is indefensible.

There remains, once again, the question whether anyone would make such a mistake. Would anyone assume that no oikeios logos could be given of the sensible elements, on the ground that the contribution of common terms or any terms of reference would 'add' to what is referred to? Plato, it has been suggested here, went on the assumption that his own division between sense-perception and the activity of the mind by itself might insinuate that. If perception itself is 'speechless' and the mind does add the commons, which it has conceived of 'by itself and which are said to be ė $\pi \grave{i} \pi \tilde{a} \sigma \mathrm{l}$ kolvóv, it is easy to think that there is some addition made, something alien introduced, when the mind attributes something to the perceived object when it determines what is common to them

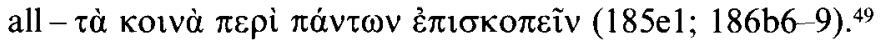

Plato's discussion of the Dream Theory has, then, neither refuted some nameless opponent, nor merely erected something like a scarecrow that shoos us away on our search for a plausible account of 'account', but it has addressed a real difficulty which his division between the functions of aisthessis and epistēme may seem to import, namely the question whether the sensibles are capable of a logos or not. The difficulty is, indeed, an important one, which is less apparent when one focuses on the obviously absurd examples, that one could not even say 'this' or 'alone'. The seriousness of the difficulty emerges, however, when one reflects on the most important example which is repeated throughout, that you could not attribute 'being' to anything. Not only is 'being' everywhere treated as the foremost of the common concepts, it is needed in all definitions since it states what they are. For you could not regard 'A is a vowel' as an oikeios logos, nor could you say how it differs from E. ${ }^{50}$ Hence no definition by genus and differentia could count as knowledge, and none of the analogismata that make up the science of letters could be proper to its subject matter!

It is time here to turn to the question why Plato did not make it clearer that the problem discussed in the Dream Theory applies to sensibles in general, if that was his intention, but deflected our attention by focusing on the 'elements', the stoicheia, right away, as if the relation between such special kinds of parts and wholes was his main concern. The answer to this question presents itself if one reflects on the admirable economy displayed by Plato's procedure. He introduces 


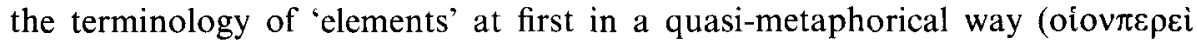

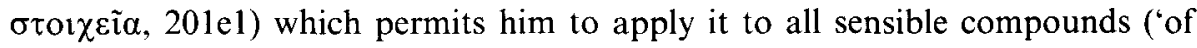
which we and everything else is composed'). This introduction then legitimises the use of letters and musical notes as paradigm cases ('as hostages', 202e). Since letters and notes are clearly discrete units, that can be distinguished from one another and whose relation in a compound can be defined, while this would be a very murky business in the case of most other sensibles (such as ourselves), they form the ideal basis for a reductio ad absurdum. For it is clear in the case of letters and syllables that neither of the alternatives in the dilemma is acceptable; while it would be not nearly so clear in the case of our ultimate parts. The dilemma works only if there are clearly recognisable parts and a recognisable way in which they form a compound. In addition, letters and notes are the subject matter of established disciplines that form part of the education of every Greek schoolboy, letters and notes are therefore excellent witnesses to the effability of parts and compounds, which the dilemma threatens to do away with.

But more than the justification of this effability has been achieved when Plato at the end of the long reductio argument presses for the point that we can 'know' the elements of each discipline, since we in fact first do get to know the elements for themselves and then learn how they fit together. As Socrates illustrates it, we first learn to discern the letters by looking at the image of the letter $\mathbf{A}$ and hear the sound ' $A$ '. And we learn to play music by learning how to associate tones and strings. Only later do we learn of the possible interrelationships between these elements and how to put them together. ${ }^{51}$ What Plato has done, then, is to show that the elements are in principle knowable and can be defined by 'adding' something to them via the common concepts. And he has indicated that 'ostensive definitions' like that in the case of 'this (pluck) is G' are possible and can be the beginning of knowledge. The admirer of Plato's later dialogues will appreciate the establishment of the elements' knowability, since the letters and musical notes are his favourite examples to illustrate how dialectic works, at various occasions. ${ }^{52}$

Yet this depiction of the process of learning and of the knowability of each discipline's subject matter imports at the same time, most economically, the reason for its downfall as a justification of knowledge. For though the elements are better known to us and primary in the process of education, they are not better known as such, as Aristotle would say. The diagnostic power by sight (206b7) turns out to be at best a necessary condition, but it is not yet knowledge, as Socrates makes clear in what follows, when he soon afterwards discards such claims to knowledge in his criticism of giving an account by enumerating the elements (206e-8b). The school-child in elementary -school does not yet know the art of writing nor does the beginner on the kithara know the tonal systems. There is something important missing. This much is already indicated by the fact that Socrates stresses so much that it is the beginner who has a much better 
comprehension of the letters than of the syllables (206b5-11), and that this was the way he and Theaetetus had learnt the art of writing (203a; 206a).

\section{Logos}

An explanation of what is missing in our initial comprehension of letters and notes, in this diagnostic power of the elements taken one by one,,$^{53}$ could have formed the basis of the further determination of the nature of knowledge. But this is not what happens; the dialogue passes over this opportunity and inexorably goes on to its (at first sight) bitter, or rather disappointing, negative end. Plato confines himself to bare hints that more could be said about the knowledge of writing when he indicates that and why beginner's luck is not knowledge. For I might have quite the right opinion how to write 'Theaetetus' and be able to spell it out in the right order, but this could turn out to be rather a shaky kind of 'knowledge', as my inability to write a similar name like Theodorus correctly would show.

That a proper dialogue on the art of writing is not confined to mere enumeration, haphazard or not, is only indicated in Socrates' critique of the conception that a logos could consist in such enumeration that leaves the compound itself unaccounted for (207c8). Of course the wagon-builder and the writing-master know more than the complete enumeration of the parts; this is suggested at least by the indication that there is a special way of 'speaking like an

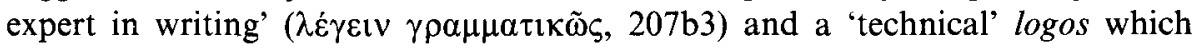
differs from mere opinion (c1-4). What makes it a professional logos, except for the completeness, Socrates does not say. Is this then another example of Plato's tendency to leave us with seminal questions because he does not want to cater to the reader's complacency by providing him with ready-made dogmatic answers?

If the final account of 'account' is not introduced as a supplement to the enumeration-account but as an equally unsuccessful alternative, this should not prevent us from asking whether it could provide such a supplement. For the possession of the specific criterion to establish the right distinctions would be the hallmark of all theoretical as well as of practical knowledge. The failure of the final attempt has therefore bothered most readers, and it should bother especially the interpretation advocated here, since in the very last attempt to give a proper account for what an account should be like, Plato finally does make quite explicit and extensive use of the common concept of 'difference', and even deigns it worthy of the introduction of the technical term diaphorotess (209a5; d1). And yet, the explicit employment of 'difference' gets Socrates nowhere. The reason given for the failure of this last attempt is clear: Socrates objects to himself that we already have to 'have' that difference when we only have the right opinion about what Theaetetus looks like and how he differs from everyone else, his unique snub-nose and protruding eyes. Any further attempt to amend the logos is equally doomed 
to failure: the move to upgrade the differentiation by distinguishing between true belief as the mere implicit 'having' of the distinguishing mark and really knowing it makes the definition hopelessly circular.

I will not try to 'save' this last argument by a full discussion, but only indicate where I, once again, see a poros for what one must realise is a genuine difficulty, and then explain why Plato does not himself proceed on this path to a positive end. ${ }^{54}$ First of all there is the possibility that Plato wanted us to realise that not just any kind of true opinion can be changed into knowledge by the addition of an 'account'. Perhaps it can (in Plato's eyes) never be a matter of knowledge how one individual differs from another. What speaks for this assumption is not just the age-old wisdom that the individual is ineffable, but a rather forcible remark in the digression earlier in the dialogue, where Socrates had worked out what distinguishes the philosopher from the forensic orator $(172 b-77 c)$. For in his characterisation of the philosopher Socrates had explained:

Because such a person really does fail to notice his next-door neighbour: he is oblivious not only of what he is doing, but almost whether he is a man or some other creature. But as for the question what, exactly, a man is, and what makes

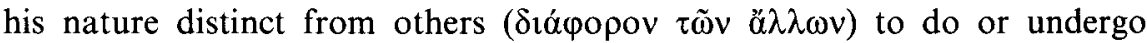

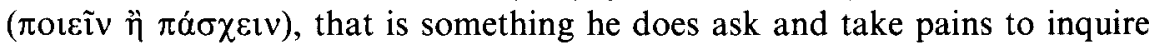
into. (174b). ${ }^{55}$

So the last argument may have gone wrong because Socrates has used the wrong example, the example of identifying a particular by its familiar traits, and the negative end would show that such things are not knowable, i.e. capable of a logos in the full sense. But does not the same objection hold for the distinction between the universal 'ox' and 'horse'? Surely we do have to be able to tell them apart, have the right opinion about a distinguishing mark, and we in fact can tell horses and oxen apart, just as we can distinguish between Theaetetus and Socrates. So we have the same problem with the distinction between knowledge and right opinion in the case of universals as we have with individuals. And it is not likely that Plato overlooked that fact, for it is equally true in the case of the elements, e.g., the letters $\mathbf{S}$ and $\mathbf{O}$, as well. The grammatikos clearly deals with types, not individual letters.

What the example of the two universals brings out, however, is that not any old distinguishing mark will do. ${ }^{56}$ Our everyday criteria, even if they are true and we can articulate them (which often we cannot!), would not satisfy a linguist. This is supported by the observation that Socrates first introduces the distinguishing-

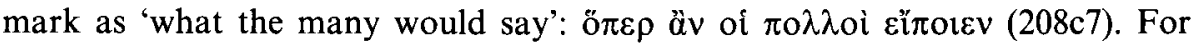
everyday purposes the right opinion about a distinguishing mark is quite enough. But being able to tell them apart by a visual criterion is not knowledge of what 
differentiates them; it certainly does not tell us what the 'being' of their difference is, as Socrates had demanded in the passage on the common concepts at $186 \mathrm{~b} 7$.

To return to the case of the school-boy: being able to to tell the elements apart by sight is not enough; such elementary cognition is a necessary but not a sufficient condition for the knowledge of writing or music. The way in which the school-boy manages to identify letters (by sight) or notes (by ear) is not the 'scientific' way of the grammarian and the musician. They have quite different ways of identifying letters and sounds. They don't have to listen to them or look at them or pluck strings; they know their characteristics and their functional interrelationships, 'what befits their nature to do or suffer', to use the expression from 174b, quite independently from such direct experience. Composing at the piano is definitely 'out'.

But does this not bring us back to knowledge of universals and forms? There is something to this suggestion, although not what the 'friends of the forms' would make of it on Plato's behalf. If the reference to the professional knowledge of the musician and the writing-master teaches us anything, then it is by pointing us in the direction of the expert's systematic knowledge, in opposition to the ordinary humdrum way of distinguishing things. The systematic investigation ascribed to the philosopher earlier in the digression and the anti-democratic sentiment conveyed by the reference to the polloi here, support this assumption.

The reason why Plato did not go further in the direction to which he points us in the Theaetetus is then not difficult to see. We would have to pursue the question what constitutes the difference between ordinary 'knowledge' and the systematic knowledge of the expert. For this seems to be the crucial point: there can be quite different dialogues in the soul, and the lay-person's is one, the scientist's or philosopher's is another. In other words, even the explicit and proper application of the koina may not be sufficient for knowledge but only for true belief. And, most importantly for the negative end of the dialogue, one statement, taken in isolation, cannot be clearly assigned to one dialogue or other. I may take a paragraph out of a textbook on Greek music and mumble something about the difference between the genos malakon and the genos syntonon without having any knowledge of the matter at all. The audience would not be able to tell, if it did not know what, if any, kind of dialogue has gone on in my soul. ${ }^{57}$ The example of the sun as the 'brightest of the heavenly bodies going around the earth' is such an ambivalent statement, it may or it may not be imbedded in knowledge of astronomy. And no further addition to it could turn an isolated statement from a mere opinion into knowledge. Whether I possess true knowledge would surface rather in a philosophical dialogue that shows whether I can successfully survive the kind of scientific examination that we find prescribed by Socrates in Rep. 7 for the dialectician $(534 \mathrm{~b} / \mathrm{c})$.

But why, if this distinction between a scientific and a non-scientific dialogue is the whole point, would Plato so mislead us by focusing on the example of 
Theaetetus and his particular looks? Is it only to bring the discussion to a quicker, negative, end? And why did he focus on sensibles most of the time in the last part? Was this just one big trap?

We should realise that what is misleading about the example of 'knowing Theaetetus' is not that it is concerned with a sensible object. Plato has been concerned with sensible objects ever since he had explicitly stated that the common concepts are applied to the pathe we experience in sense-perception (186b).$^{58}$ It was the example of hardness and softness that Socrates claims the mind works on: 'But their being and that they both are, and their oppositeness to each other, and the being, in its turn, of this oppositeness, are things which the mind itself tries to decide for us, by reviewing them and comparing them with one another.' If Plato had misled us, he would have done so not only with his last example but at the very beginning of the investigation of the question of doxa and episteme $\bar{e}$ by speaking of sensory objects in the first place.

If there is anything misleading in the example of 'knowing Theaetetus', then it would lie in the fact that in this particular case knowledge and true belief may seem indistinguishable. But I do not think that Plato has misled us in that way either. We should remember that the dialogue has started (143e) and ended with the discussion of snub-nosedness and protruding eyes $(209 \mathrm{cl} ; 5)$. And we should remember that at the beginning Socrates had brushed aside Theodorus' claim that Theaetetus resembled him in that respect as being a matter to decide for an expert in likeness. It would be a draughtsman's (graphikos) business to determine such matters, and Theodorus was not that but a geometer. So there is no need to listen to him, he would not know (144d $45 \mathrm{a})$. If this was not just pleasant Socratic rudeness it would suggest that there can be a knowledgeable dialogue about the peculiarities of Theaetetus' snub-nose versus Socrates' by such an expert. ${ }^{59}$ This, however, is not the mathematician's or the philosopher's business, but the draughtsman's. Philosophers can, of course, have their own dialogue about snubnosedness, what its being is, and how it differs from all other things. As we know, one can get quite some metaphysical insights out of snub-nosedness. Where would Aristotle's Metaphysics $Z$ be without the snub? The Platonic philosopher might, however, rather prefer to engage in a dialogue about the difference between external and internal beauty in order to finally get rid of the bothersome claim that Socrates and Theaetetus are ugly $(210 \mathrm{~d} 1) .{ }^{60}$

The draughtsman does not reach those higher echelons of the philosopher's discussion which explicitly, systematically, and reflectively employs these "common concepts', but that does not mean that he has not his own field of knowledge: he deals with the being, not-being, sameness, and difference, beauty and usefulness of a certain kind, that is, of the shape of objects of sight qua sight, so that he can tell us all about the difference between snub and snub.

If there is anything misleading in the whole strategy of the Theaetetus' last part then it lies in the focus of the discussion on particular 'pieces of knowledge'. ${ }^{61}$ As 
we should realise, one piece of knowledge cannot be distinguished from a piece of true opinion. One swallow does not make a summer. And a one-sentence logos does not make for a proper dialogue. Whatever else we may be supposed to make of the Aviary, it made at least clear that grabbing free-fluttering 'pieces of knowledge' would not do for epistemēe. ${ }^{62}$

But if this ambiguity about knowledge as an interrelated field is not resolved, this only means that by the negative end of the Theaetetus Plato points us beyond the discussion of this dialogue, to the need for a fuller discussion of what systematic knowledge is, which would explain among other things, the nature and interrelationship of the common concepts themselves, a discussion that we are going to find in the Sophist. A full comprehension of the common concepts would also presuppose, it seems, the painful but necessary exercises of the second part of the Parmenides as well as the discussion of the unity and limitations of a field of knowledge in the Philebus. This is not to say that we can only understand the final discussion in the Theaetetus if we read the later doctrine into it; what Socrates has suggested about the grammarian's or the musician's knowledge, who have their own 'scientific' dialogue, ${ }^{63}$ is quite sufficient as an illustration of the analogismata recommended at $184-6$ as the soul's own business. ${ }^{64}$ And Socrates had actually not promised anything more in the Theaetetus. He had only promised to deliver Theaetetus of his preconceived opinions about knowledge; it would have been most implausible to attribute to young Theaetetus the comprehension of systematic knowledge beyond the first glimpse he has had of it in his own field of expertise, i.e. mathematics. We should not forget that Theaetetus had displayed his aptitude to make proper systematic distinctions in his own field when he found a device to differentiate between rational and irrational square numbers $(147 \mathrm{c}-48 \mathrm{~b})$. He just had not yet seen the full importance of this method for the determination of what knowledge itself is.

\section{Peroratio}

To sum up: the Theaetetus is not an a-poretic dialogue since there is at least the indication of a poros. But there is no more than an indication of the direction which the way out must take. Plato's theory of the Forms is, however, not a theory waiting to be pulled out of a magic hat, ready to solve all problems: the last part of the Theaetetus is in fact designed to show what preliminary difficulties have to be solved. Since knowledge and belief no longer have separate objects for Plato, it is necessary to work out how they differ: that is, in the way they handle the same objects. There is, however, no gap in Plato's psychology between perception and knowledge; for the different ways in which the mind applies the koina explains the different kinds of judgements, ordinary simple judgements on the one hand and knowledgeable judgements on the other. Plato had very cunningly hidden the dual function of the common concepts in the suggestion 
that knowledge is contained 'in' our calculations rather than that they are knowledge (186d). For not all of them do attain knowledge. This double entendre explains the further stages of the investigation: The need to work towards a proper separation of knowledge and true belief is the reason why the "promising line' is not pursued in a more open and direct way. The excursus into the problem of false beliefs gives us some advice of how to handle the common concepts in our silent dialogues; the investigation of 'true opinion with an account' explains why even the proper handling of common concepts in our everyday silent dialogues may not be sufficient to turn our correct opinions into knowledge. If the koina are the Forms, then their successful employment depends on further study into their nature and interconnections which Plato had recommended in 184-6, as the 'analogismata into their being and usefulness, which are acquired just barely over a long time, through a lot of difficulty and education by those who in fact do acquire them'.

As far as this ability is concerned, we are given only a promissory note in the Theaetetus. If Plato has not guided us on a straight and narrow path through the woods of epistemology then he has certainly guided us into the woods in the right way, by showing us the host of problems that have to be mastered. ${ }^{65}$ The common concepts and the field-theory of knowledge that makes proper use of them are, then, introduced in the Theaetetus as a good idea whose own time is yet to come. ${ }^{66}$

\section{NOTES}

1. That Plato quite intentionally leaves us in the dark and forces every one of us to start putting the pieces of the puzzle together again and again in order to prevent a passive absorption of his doctrine, is the conclusion to be drawn from the famous passage which explains the inferiority of the written against the spoken word in the Phaedrus $(274 \mathrm{~b}-7 \mathrm{a})$.

2. An example of such a hint can be found in the Euthyphro where Socrates gives us a clue as to what

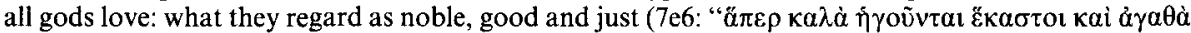

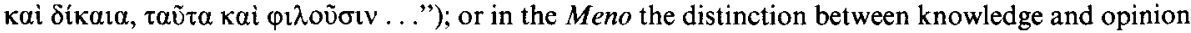
as Daedalus' flightly children who need to be tied down (97d). In Rep. 1 the 'functional argument' (cf. 352 eff. on the specific ergon and the proper virtue) at least foreshadows the later definition of justice as 'doing your own thing'. It is not difficult to detect such hints; why Plato does not pursue them must remain a matter of speculation.

3. For a discussion of Plato's own explicit treatment of the conception of aporia cf. M. M. Mackenzie, 'Impasse and explanation: from the Lysis to the Phaedo', AGph. 70 (1988) 15-45; esp. 15-24.

4. I have to gloss here over the troublesome details of Plato's distinction between the souls' faculties. For a detailed analysis of Plato's treatment of sensation and the conception of a unified perceiving 
consciousness see M. Burnyeat, 'Plato on the grammar of perceiving', Classical Quarterly 26 (1976) 29-51; M. Frede, 'Observations on perception in Plato's later dialogues', Essays in ancient philosophy (1987) 3-8. I share the view that Plato treats the senses as devoid of any power of judgment. The opposite view that perception involves at least the 'labelling' of the percepts is defended (with reservations) by J. Cooper, 'Plato on sense-perception and knowledge, (Theaetetus 184-186)', Phronesis 15 (1970) 123-46. This view is based on the assumption that we always immediately label our sensations, such as 'red' or 'bitter'. Against this assumption it should be pointed out that the habitual labelling may be undeniable for such routine experiences but not, eg., for nuances of colours (reseda-green), unusual tastes, and not at all for sounds. Few of us are able to label a sound as 'b-flat' immediately!

5. For this achievement Theaetetus gets high praise. He is called beautiful, not ugly (185e3), because he liberates Socrates from the heavy task of having to argue for the dichotomy between what the soul does by itself and what it does through the capacities of the body.

6. That only highly abstract terms are mentioned may be a matter of sheer argumentative economy: Socrates would, at this point, find it hard to convince Theaetetus that less abstract concepts like 'dog' or 'colour' are not the product of perception but of the mind 'by itself'. Plato is silent about the question where these concepts belong. Perhaps we may assume that we learn the names 'dog' or 'colour' through perception but not the concepts themselves. The problem is compounded by the fact that Plato does not tell us in the Theaetetus what faculty procures a synthesis of a complex perceptible object.

7. He even apologises for the fastidiousness and verbal precision necessary in this investigation $(184 c)$.

8. It has been debated whether sensation is a mere passive affection of the soul. For this claim cf. the arguments by M. Frede (n.3). Against it ef. Burnyeat (n.4), who points out why it is not necessary to read Plato this way (cf. p.42f). Against Burnyeat's argument that we intentionally employ our senses to gain access to and to investigate sensible qualities (43), it should be noted that the employment is not determined by the affection itself. Nothing hinges on this question for my further interpretation, but it should be noted that since the soul in sensation seems merely to receive the pathemata, a passive reading would seem more appropriate. The difficulties for the view that Plato already assigns rudimentary judgments to the senses ('this is red') come to the fore in Modrak's defence ('Perception and Judgment in the Theaetetus', Phronesis 26 (1981) 35-54). She ascribes an implicit possession of concepts to the senses (cf. 43: 'the notions are indifferently and incompletely given in the perceptions of all senses'; 44: 'It uses concepts that are implicitly given in the sensuous representation'). There is, however, absolutely no textual evidence for any such 'implicit containment' of concepts in the senses, and all evidence speaks for the view that the judgment 'this is red', since it asserts being, is a function of the mind itself.

9. On the much-debated question of the meaning of 'being' (ousia) in this passage cf. Burnyeat (n.4) 44-5. I follow his recommendation that when Plato says that the mind determines 'being' or 'notbeing' of perceptions he should be understood in the sense that 'each of them is and is not because they are and are not various things'. At times it seems best to translate ousia by 'nature' as at 186b7: the nature of their contrariety, i.e. what it is. Cf. also C. Kahn, "Some philosophical uses of "to be" in Plato', Phronesis 26 (1981) 105-34, esp. 119-27.

10. The extreme Heraclitean theory of sense-perception is here treated as discarded. Socrates now assumes that perceptions have a definite nature and put us in touch with independently existing objects. 
11. This revokes Socrates' assumption at $179 \mathrm{c}$ that with respect to the actual affections both perceptions and doxai might always be true. Perceptions seem to remain incontestable (materially), while the doxai depend on the correctness of the analogismata.

12. I will not make any decisions about the difficult question whence the soul gets the concepts of reflection, since Plato does not tell us anything about them beyond the fact that the mind has them and uses them. For a criticism of Cornford's and Cherniss' claim that the contemplation of the Forms of Being, Likeness ... themselves is at stake cf. Cooper $125 / 6$.

13. Cf. Parm. 129d-e: 'likeness and unlikeness, plurality and unity, rest and motion and all that'. Being, Sameness, and Difference are also said to be parts of the world-soul in Tim. 37a-c, and its capacity to reason rests on them. The differentiation of sameness and difference is called the 'road to reason' at $44 a-c$. No further help will be sought from these parallels in other dialogues for the interpretation of the Theaetetus, not only because this would go beyond the bounds of a paper but because each dialogue should, as far as possible, be treated as a self-contained and -explanatory unity.

14. 'All but a definition' may be an overstatement. At best we have here a formal indication that knowledge must consist in the reflective employment of the common concepts; it does not tell us anything about the kind of employment, the extent or the degree of explicitness that would guarantee the achievement of 'being and truth'. As will be seen later this question is indeed crucial for the problem of the distinction between knowledge and opinion. Apart from the crucial passage at 186b69 which indicates that Plato has a systematic procedure in mind, he also gives at least a hint that progress has been made towards the depiction of epistemen at $187 \mathrm{a}$ : 'We have made enough progress to stop looking for it in perception altogether and look for it in whatever one calls what the mind is doing when it is busying itself, by itself, about the things which are.'

15. Cf. n.7. That there is indeed a wide gap between full knowledge and perception, and in what sense the distinction between knowledge and true opinion fills this gap, will emerge in the further discussion of the difficulties that stand in the way to a proper distinction.

16. Socrates in fact seems to check Theaetetus at this point (186b2: "hold off' - " $\check{\chi} \chi \varepsilon \delta$ ' it that the 'calculations' are extrapolations from the past and present to the future, since future states of affairs cannot be grasped by perception. Theaetetus sees here a reference to the question of the knowledge of future states of affairs discussed earlier (178c-9b), but Socrates is not concerned with such practical calculations but with that concerning the ousia of the perceived qualities.

17. The article by J. T. Bedu-Addo, 'Plato on the object of knowledge' in A. Gotthelf (ed.) Aristotle on nature and living things (1985) 301-11), argues also for such a double reading. He takes it, however, that Plato clearly wants us to opt for the alternative which consists in 'pure reasoning' (with a Kantian flavour, 309) about the 'real nature' of the objects of the mind, and sees therefore no difference between the koina and the Forms of the middle dialogues. His exclusive identification of ousia with 'real nature' seems to be misguided, however, and leads to a very one-sided reading of the text.

18. Paideia certainly need not be 'the way out' of the Cave (Rep. 514a; 518b7); but it is hard to believe that Plato meant by the paideia that helps achieve ousia and opheleia the bare learning of speech. Earlier in the dialogue Theaetetus had identified paideia with the liberal arts (145a; cf. also the distinction between paideia and the demiurgic' disciplines in Soph. 229d2, suggested by Theaetetus himself?). The employment of mogis reminds one of Socrates' claim in Rep.7 that the Form of the Good is 'just barely seen'- $\mu$ ó $\gamma 1 \varsigma \delta \rho \tilde{\tau} \tau \alpha 1(517 \mathrm{cl}$, cf. Phdr. 248a4 where it is said of the soul that it is

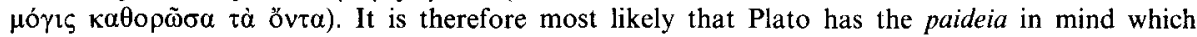
characterises the philosopher who does not spare any trouble to find truth, in the excursus on the true philosophic nature (172-7). 
19. Socrates even indicates that he thinks they ought to "wipe out everything that had been agreed on

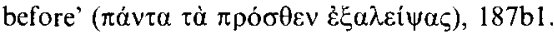

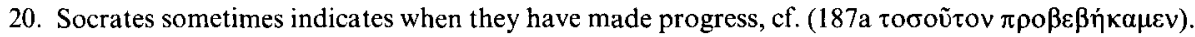
The Wax-Tablet is vindicated later as constituting true (and thus by implication also false) opinion, but not more than that $(290 \mathrm{c})$.

21. The 'all-or-nothing position' underlies Meno's paradox. It is exploited in the Euthydemus.

22. Cf., eg., Phaedo 76b5. Most significant is the fact that in the Theaetetus itself the ability to give an account is mentioned as a decisive characteristic that distinguishes the true philosopher from the forensic orator, the man 'with a small and sharp mind' (175c).

23. More will be said later concerning the attribution and interpretation of the Dream-Theory.

24. See the account of dialectic in Rep. $535 \mathrm{~b} / \mathrm{c}$ and $P h d r .263 \mathrm{bff}$.

25. F. M. Cornford, Plato's theory of knowledge (1935) 102-9. For a critical discussion of this view cf. Cooper (n.4) $123-6$.

26. To keep the discussion within reasonable limits only those contributions are mentioned of the extensive secondary literature that are directly relevant to this interpretation.

27. The term koinon is not used in that sense again. For what is called koinon in the final argument (208d8; 209a 10) are common, as opposed to differentiating, properties.

28. That Theaetetus is not quite taken in is indicated at 191b. It may indeed be often his easy temperament and readiness to learn (144a) that makes him go along with Socrates instead of insisting on his own, often quite justifiable insights.

29. For a detailed discussion ef. McDowell, Plato's Theaetetus (1973) 194 209; 235-9. McDowell, however, goes on the assumption that Plato did not see the fallaciousness of his own arguments, although he allows that there are indications that Plato 'is not happy with them', (208).

30. Initially it is supposed to improve the deficiency of (1) and (2) by explaining how allodoxia, ie. thinking that one thing is another, is possible, but it ends by asserting its impossibility.

31. If Plato is concerned with the conditions of applying common terms it is clear why he is dealing with terms of judgement rather than states of affairs, as McDowell (n.29) expresses it (198).

32. That it is the unclarity about a thing's identity that causes the trouble seems indicated by the phrases $\tilde{\omega} v \tau \imath$ of $\delta \varepsilon$ and $\tilde{\omega} v \mu$ iे of $\delta \varepsilon(188 \mathrm{a} 7 ; \mathrm{b} 8)$. It leaves room for the possibility that I may know the object under one description but not under another, or that $I$ may not recognise it in the present circumstances, while being otherwise quite familiar with it.

33. This problem is not really cleared up in the Tht.; but the indication of an ambiguity in 'not being' $(188 \mathrm{~d} 9 / 10)$ points forward to the solution in the Sophist. Plato presumably wanted to provoke some reflections here on the question in what way 'thinking what is not' differs from 'seeing or hearing what is not'. 
34. A more sophisticated depiction of the problems in modern jargon (de dicto and de re, referential opacity) has been worked out by D. Bostock, Plato's Theaetetus (1988) 161-76.

35. The discussion focuses almost exclusively on mistakes of identity (the exception is the second paradox which deals with the ambiguity of being and not-being). It is not clear whether Plato concentrated on them because he thought them the most obvious, easiest to demonstrate, or whether he thought that all judgements involve the establishment of identity before any of the other koina can be applied. Establishing the identity of an item would then always be the first problem. Cooper (n.4) $134 \mathrm{n}$. 14) expresses some puzzlement as to what Plato means by self-identity. Plato may have had no more than the identification of the object in mind; but he was also aware of other problems, such as the question of identity over time. Is, eg., the Theaetetus who has outgrown Socrates the same as he was before? For sameness and difference in change cf. Tim. 35a-36d.

36. In the Sophist the doctrine that a dianoia is the result of a silent dialogue is treated as established $(263 \mathrm{e}-4 \mathrm{a})$.

37. One difficulty lies in Socrates' not spelling out explicitly whether the mistake is propositional or not. Cf. F. Lewis, 'Foul play in Plato's aviary', in Lee et al. (eds.) Exegesis and argument (1973), $262-84$.

38. If the reader is somewhat relieved to see Socrates debunk the Aviary then this is largely due to the theoretical implications of this model: it seems to presuppose a very primitive theory of predication, as some interpreters have suggested, that Plato was to overcome only in the Sophist (cf. McDowell (n.29) 219ff.). But I do not think that this interpretation can be right, if it assumes that Plato regards all cases of false judgement as cases of mistaken identity. For the list of common concepts suggests that he envisaged quite a host of mistakes: mistakes about being, sameness, difference, likeness, unlikeness, number, goodness, beauty, usefulness.

39. Cf. $200 \mathrm{c} / \mathrm{d}$. I regard this as not a mere subterfuge to end the unsuccessful discussion.

40. For a discussion of this passage cf. McDowell (n.29) 228-31. That Theaetetus only now remembers this important definition can be explained as a case of recollection prompted by Socrates' criticism of the forensic orator's inability to procure knowledge: Socrates had mentioned his inability to 'teach sufficiently' the truth about the matter in his race against the water-clock (201b3). Theaetetus would have realised that a 'proper account' could make up for this deficiency ( $\delta 1 \delta \dot{\alpha} \sigma \kappa \varepsilon i v i \kappa a v \tilde{\omega} \varsigma)$. The shift is thus not quite as impromptu as some interpreters have assumed but represents a classical case where anamnessis is caused by the right kind of questioning. It must remain an open question whether for Plato any amount of additional logoi could turn the witness' testimony into knowledge.

41. For a comprehensive discussion of the Dream and the unlikeliness that Plato addresses another author cf. M. Burnyeat, 'The material and sources of Socreates' dream', Phronesis 15 (1970) 101-22; McDowell (n.29) 234-9.

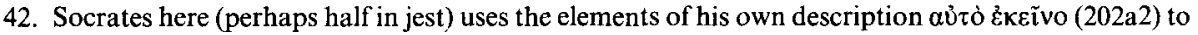
indicate that even this much cannot be properly said of the elements.

43. Cf. Burnyeat (n.41) 120.

44. Nor does, therefore, the polythryletton apply here that Plato does not distinguish between 'knowing by acquaintance' (connaitre) and 'knowing that' (savoir) (cf. McDowell (n.29) 231ff.). You may claim to 'know' any number of facts about the elements, according to the Dream Theory, without knowing them. Socrates does not forbid Theaetetus to say other things about them, as indeed 
he does soon afterwards; he says that $\mathrm{S}$ belongs to the consonants and is 'only a sound', 203b; both est $i$ and monon had been excluded in 201e/202a as 'adding something'.

45. Cf. the article by G. Fine, 'Knowledge and logos in the Theaetetus', Philosphical Review 88 (1979) 366-97. She realises that the salient point is that a logos must be proprietory (oikeios) but wrongly supposes that this means that the logos must say something 'towards analyzing or fully explaining it' (374). No theory of what a full explanation would have to be like lurks behind the Dream Theory. It merely rules out that anything oikeion can be said about the elements either by (any) attribution or by pointing to parts.

46. The list of attributes ruled out by the Dream Theory is only partially identical with the common concepts listed in 184-6; but this need only indicate that the misunderstanding is not specifically turned against Plato's own candidates as alien additions (although being and not-being stick out as prime candidates), but against anything that can be regarded as 'common', even pronouns.

47. Any interrelational account at this point would be ruled out a fortiori by our inability to give an account by even as much as referring to the elements, let alone by differentiating them from one another, in the way Plato had described as necessary for the proper employment of the common concepts. Theaetetus rightly recognises that his descriptions of the letters (203b) cannot, given the conditions of the dilemma, be regarded as logoi. The establishment of an 'interrelational' account of 'account' that Fine sees in this passage (380) is here then at best foreshadowed.

48. An example for such a nexus would be the thesis of the letters (206a7). One could not attribute 'common descriptions' like 'this next to that' to describe the order of the letters in the syllable in order to define it. In defending the soundness of the dilemma I do not subscribe to the fairness of all its moves; especially the claim in the mathematical example that the sum and the whole are the same $(204 \mathrm{~b} / \mathrm{c})$ is highly dubious. Plato may have wanted to signify by its very dubiousness that once the Dream Theory is discarded, definitions in terms of constitutive parts can be resurrected (cf. McDowell (n.29) 244; 249).

49. Cf. esp. $\pi \varepsilon \rho l \tau \rho \varepsilon ́ \chi 0 \nu \tau \alpha \pi \tilde{\alpha} \sigma l \pi \rho \circ \sigma \varphi \dot{\varepsilon} \rho \varepsilon \sigma \theta \alpha \mathrm{l}$ (202a5) with the phrase at 186a3, where it is said of being that it 'goes with everything' as if it were a separate item ( $\dot{\varepsilon} \pi \dot{i} \pi \dot{\alpha} \nu \tau \omega \nu \pi \alpha \rho \dot{\pi} \pi \varepsilon \tau \alpha 1)$.

50. Socrates and Theaetetus are quite aware of the dire consequences of the addition-theory, for Theaetetus agrees that despite his 'definition' of $\mathbf{S}$ as a hissing consonant, and of $\mathbf{B}$ as a mute one, they remain aloga (203b).

51. The method of teaching consists in the identification of each letter in a word by pointing to them in succession. We thus avoid beginner's confusion which arises when they are spoken or written in connection (thesei: we should remember the extra confusion caused by the fact that there was no space

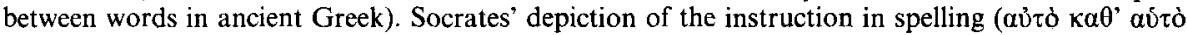

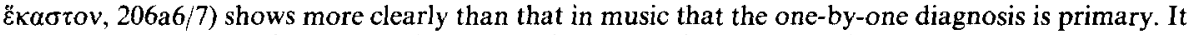
is therefore a mistake if Fine regards this description as a justification of the 'interrelational method' $(385 / 6)$. At stake is not yet the system of the notes on strings but the name of the note on each string. How the notes are combined in the different modes is a much more complicated affair, as everyone knows who has tried to study the arcana of Greek music.

52. Cf. Phil. $17 \mathrm{a}-18 \mathrm{~d}$; Soph. $252 \mathrm{e}-3 \mathrm{a}$; a techne is necessary to determine what combinations are possible.

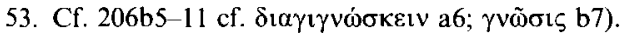


54. A different interpretation is attempted by R. Desjardins, 'The horns of the dilemma', Ancient Philosophy 2 (1979) 109-26. Her 'conciliatory' solution seems to me untenable. Plato does not call what unifies the whole its 'differentiating form' (120; nor can one see that 'true opinion' contains the elements of knowledge while the 'account' contains the differentiating form (of the true opinions?) (12); nor does Desjardins show how this should help to improve Plato's last example: how we can know (vs. truly believe) that this is Theaetetus on account of his snub-nose.

55. The necessity to establish systematically the active and passive capacities of the subject matter in

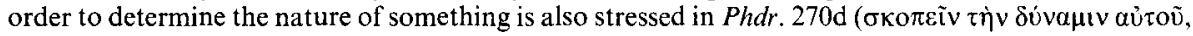

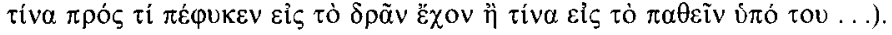

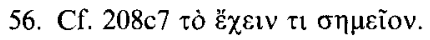

57. I agree here with $G$. Fine's position that no particular true statement taken in isolation can be regarded as knowledge ( $\mathrm{n}, 45) 95$ et pass.

58. Reflection on the Forms is in fact concerned with the application to sensibles already in the Phaedo (74aff) and the Republic (cf. 'the fingers' 523aff).

59. If this sounds like an over-interpretation of a light remark we should keep in mind Plato's assertion in the Sophist (227a-6), that nothing is too little to interest and serve the true dialectician. There is no reason why Plato should not ascribe the same type of technical knowledge to the draughtsman that he grants to the musician and the linguist.

60. If one applies these possibilities to the seminal discussion of the koina at $184-6$, one can argue for a triple entendre instead of the double entendre advocated above. There is (1) the ordinary dialogue which unreflectively and 'unaccountably' employs the koina, and does not achieve knowledge but only true opinion. There is (2) the dialogue of the specialist which reflects on the common concepts insofar as they apply to the special science. And there is (3) the dialectician's dialogue which reflects on the common concepts and their interrelations themselves, as discussed later in the Sophist (cf. 253b-e:

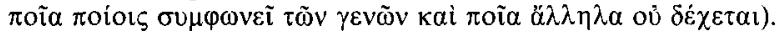

61. At the very worst one can say that Theaetetus' looks represent a philosophically unexciting example since it does not incite us to further questioning, just as the finger in the example of the Republic does not (523c).

62. This was explicit in the Aviary, cf. 197e3; 198a1; a 7; 199b2. It is rather significant that Socrates there speaks of knowing arithmetic as having 'knowledges'- $\dot{\varepsilon} \pi \iota \tau \tau \eta \mu_{\alpha} \tau \tilde{\omega} \nu \tilde{\alpha} \rho \mathrm{l} \theta \mu \tilde{\omega} \nu, 198 \mathrm{bl}$.

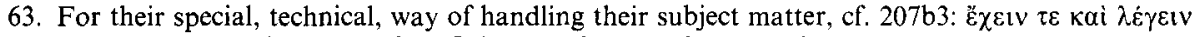

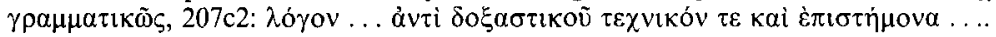

64. Cf. the criticism of Fine's interpretation by D. Bostock (n.34) 216-18;243-50. Fine has to import some of the principles from other dialogues, e.g. her $K L$ condition, i.e. of what constitutes a proper logos. She does not realise that the interrelational account is quite justifiable if one takes it as an explication of what Plato had indicated in 184-6: the need for a proper and systematic employment of the koina.

65. For a discussion that covers the same ground and emphasises the open-endedness of Plato's method ef. the monograph by E. Heitsch. Überlegungen Platons im Theaitet, (1988) and the same author's article 'Platons Dialoge und Platons Leser', Rheinisches Museum 131 (1988), 216-38. They came into my hands too late to permit a fruitful comparison. 
66. An ancestor of this paper was read as part of a panel at the convention of the American Philosophical Association in Portland/Oregon in March 1988. Later versions were presented to the Oxford Philological Society and to the Cambridge Philological Society. The paper has greatly benefited from the discussions. I want to thank all those whose penetrating questions have forced me to tighten my arguments and to strengthen my evidence, especially Jonathan Barnes, Lesley Brown, David Charles and Michael Woods in Oxford; and Myles Burnyeat, Geoffrey Lloyd, M. M. Mackenzie and David Sedley in Cambridge. 